\title{
Defining System Requirements for Simplified Blood Culture to Enable Widespread Use in Resource-Limited Settings
}

\author{
Peter J. Dailey ${ }^{1,2,+} \mathbb{D}$, Jennifer Osborn ${ }^{1,+}$, Elizabeth A. Ashley ${ }^{3,4} \mathbb{D}$, Ellen Jo Baron ${ }^{5}$, \\ David A. B. Dance 3,6,7 D, Daniela Fusco ${ }^{8,9}$, Caterina Fanello ${ }^{3,10}$, Yukari C. Manabe ${ }^{11}$, \\ Margaret Mokomane ${ }^{12}$, Paul N. Newton ${ }^{3,6,7}$, Belay Tessema ${ }^{13} \mathbb{D}$, Chris Isaacs ${ }^{1}$ and \\ Sabine Dittrich ${ }^{1, *}$
}

1 Foundation for Innovative New Diagnostics (FIND), Malaria and Fever Program, Chemine des Mines 9, Geneva 1202, Switzerland; Peter.Dailey@finddx.org (P.J.D.); jennifer.osborn@finddx.org (J.O.); chris.isaacs@connected-dx.com (C.I.)

2 Division of Infectious Disease \& Vaccinology, School of Public Health, University of California, Berkeley 94720, CA, USA

3 Centre for Tropical Medicine and Global Health, Nuffield Department of Medicine, University of Oxford, Oxford OX1 3SY, UK; liz@tropmedres.ac (E.A.A.); david.d@tropmedres.ac (D.A.B.D.);

Caterina@tropmedres.ac (C.F.); Paul.Newton@tropmedres.ac (P.N.N.)

4 Myanmar Oxford Clinical Research Unit, Yangon, Myanmar

5 Department of Pathology, Stanford University, Palo Alto 94304, CA, USA; ejbaron@stanford.edu

6 Lao-Oxford-Mahosot Hospital-Wellcome Trust Research Unit, Microbiology Laboratory, Mahosot Hospital, Vientiane, Lao PDR

7 Faculty of Infectious and Tropical Diseases, London School of Hygiene and Tropical Medicine, London WC1E 7HT, UK

8 Pole of Clinical Research, French Institute of Health and Medical Research, Paris 75013, France; fusco@bnitm.de

9 Department of Epidemiology of Infectious Diseases, Bernhard Nocht Institute for Tropical Medicine, Hamburg 20359, Germany

10 Kinshasa Mahidol Oxford Research Unit, University of Oxford and Kinshasa School of Public Health, Kinshasa, The Democratic Republic of Congo

11 Division of Infectious Diseases, Department of Medicine, School of Medicine, Johns Hopkins School of Medicine, Baltimore, MD 21205, USA; ymanabe@jhmi.edu

12 National Health Laboratory, Gaborone, Botswana; bafanamargaret@gmail.com

13 Department of Medical Microbiology, College of Medicine and Health Sciences, University of Gondar, Gondar, Ethiopia; bt1488@yahoo.com

* Correspondence: sabine.dittrich@finddx.org

+ These authors contributed equally to this work.

Received: 15 October 2018; Accepted: 26 December 2018; Published: 11 January 2019

\begin{abstract}
Bacterial blood stream infections (BSI) are a common cause of mortality and morbidity globally. As the causative agents and the resulting treatment decisions vary, near-patient testing and surveillance tools are necessary to monitor bacterial causes and resistance to antimicrobial agents. The gold standard to identify BSIs is blood culture (BC), a methodology not widely available in resource-limited settings. The aim of the study was to map out a target product profile of a simplified BC system (SBCS) to inform product development efforts. To identify the desired characteristics of a SBCS, we enlisted a small group of specialists working in Africa and Asia. Questions were used to understand challenges and how these constraints inform system requirements. The specialists were infectious disease physicians, public health/clinical microbiologists, clinical researchers, and technology experts with different geographical backgrounds. All suggested that BC should ideally be available at the district hospital level. Many of the same operational challenges, such as limited availability of culture bottles, electricity and internet connectivity, profuse dust,
\end{abstract}


the lack of ambient temperature control, and human capacity constraints were identified across the different regions. BCs, although the accepted gold standard for diagnosis of BSIs, are not widely available outside of reference/research centers in Africa and Asia. To extend the reach of this important tool, it is crucial to engage product developers and academic research partners to develop accessible alternatives.

Keywords: blood culture; hemoculture; target product profile; low- and middle-income countries; LMICs; resource limited; microbiology; AMR; sepsis

\section{Introduction}

The World Health Assembly and World Health Organization (WHO) have recognized sepsis as a global public health priority [1]. Sepsis is a major worldwide health and economic burden [2] and it has been estimated that there are 31 million cases of sepsis per year worldwide with 6 million patient deaths [1]. Sepsis is also a frequent cause of the death of neonates and children less than 5 years of age [3]. Blood culture is an essential laboratory procedure that can influence the treatment of patients with sepsis [4]. Results of blood cultures (BCs) also play a critical role in informing regional empiric therapy guidelines and the tracking of antimicrobial susceptibility trends and patterns [2]. BC was pioneered in the early and mid-20th century [5] with minor later improvements in the method due to the automated detection of positive BCs [6]. In recent years, new technologies were developed to enable more rapid identification of pathogens and detection of resistance markers from positive $\mathrm{BCs}$ [7]. However, they have not replaced the basic elements of conventional $\mathrm{BC}$ or the testing that is required following the detection of a positive sample, like identification (ID) of the organism and antimicrobial susceptibility testing (AST). To this day, BC remains the gold standard method to detect bloodstream infections and for tracking of antimicrobial resistance (AMR), despite being labor intensive and complex [4]. Unfortunately, clinical microbiology laboratory capacity is limited and underutilized in many low- and middle-income countries (LMIC) [8-12], a shortcoming increasingly recognized in the context of AMR interventions and surveillance. BCs are challenging to implement due to the length of time to return results to patients and the perceived lack of impact on treatment. Further, there is a necessity for sophisticated laboratory facilities and high costs due to the need for a multitude of different reagents. Further, highly-trained staff is also required at all steps, requiring sophisticated sustainable capacity implementation. Uptake by clinicians may also be poor due to the length of time from sample collection to result and inadequate liaison between the laboratory and wards and the often-perceived lack of quality and utility of the results from the laboratory $[8,10,13]$. Recent international initiatives have been directed at improving laboratory capabilities in low-resource areas with a specific focus on general microbiology facilities [14,15]. Along with the extensive capacity improvement activities that are ongoing to support the global fight against rising AMR, there is a need to enrich the diagnostic landscape with new tools appropriate for use in these regions [16]. The purpose of this work was to draft a target product profile (TPP) to inform product developers of the requirements of a simplified BC system applicable in resource-limited settings. TPPs inform academic and commercial product developers of key characteristics and the performance specifications of a test system that are required to meet the end users' needs for a defined use case [17-19]. Beyond informing technology innovators, the development of TPPs helps to raise the profile and promote the need for a certain type of diagnostic tool. TPPs include optimal and minimal definitions for each test performance characteristic. Optimal characteristics describe the ideal, but often technically challenging, specifications. The minimal requirements define the user needs essential to meet the intended use of the test system to be a useful diagnostic tool. Ideally, products should be designed to achieve as many of the optimal characteristics as feasible, while still satisfying the minimal criteria for all defined features. 
We sought to define product features that address challenges specific to resource-limited settings and encourage product development efforts for simplified BC systems that are suitable for these localities and could be used as near-patient tests hospitals outside of the big reference centers.

\section{Materials and Methods}

\subsection{Specialist Interviews}

A series of eight interviews (nine individuals at eight separate locations) were conducted to explore the needs and barriers for performing BCs in resource limited settings (authors: E.A.A., E.J.B., D.A.B.D., D.F., Y.C.M., M.M., P.N.N., and B.T.). Stakeholders were a convenient sample of experts with relevant and regional expertise. Stakeholders included infectious disease physicians $(n=3)$, public health/clinical microbiologists $(n=4)$, a clinical researcher $(n=1)$, and a technology expert $(n=1)$. They were based at hospitals in Asia $(n=3)$ and Africa $(n=5)$, or in the USA (and multiple low-resource areas $=1$ ). Stakeholders were selected to represent laboratory settings ranging from level 4 to level 2 health facilities [20], with or without ongoing BC testing capacity. Interviewees were selected to represent experiences from different regions and levels of capacity to establish needs and gaps across a spectrum of laboratories, settings and cultures. All were affiliated with public sector sites and/or academic institutions. Structured phone interviews ( 60-120 $\mathrm{min})$ were conducted using an interview guide that included an overview of the workflow of standard BCs to guide the discussion. Specific questions were developed by the FIND-team (authors: P.J.D., J.O., and S.D.), which addressed each BC process step from sample collection to results to understand current procedures, needs, and challenges (Supplementary Materials). The same guidance documents were used for all calls and the same interviewers were in the calls to avoid bias. The aim was to summarizes a broad range of topics that could which were then used as the basis of a more simplified blood culture system, assuming that the current system was suboptimal. Responses were summarized in an Excel database and, after obtaining oral or consent, all interviews were voice recorded for later verification. Commonalities between respondents were summarized and key findings were distilled from these records.

\subsection{Target Product Profile Development Process}

A list of the essential product characteristics for a simplified BC system was compiled based on FIND internal templates (https:/ / www.finddx.org/target-product-profiles/). These key characteristics and the responses from the interviews were used to develop an initial TPP draft. Published standards and guidelines for conventional BC system requirements were also incorporated into some of the minimal and optimal characteristics, where applicable [20,21]. To obtain the TPP presented here, an adapted Delphi-like process [18] was used. In brief, the first draft of the TPP was developed from the interview responses and shared with all specialists, then comments and corrections were collected and incorporated for the next version. The second draft of the TPP was shared back and agreement was thought for more controversial characteristics in individual communication. Previous published definitions [22] for the health system levels were used in the TPP and "near-patient testing" in this case does include laboratory testing, albeit outside of big reference centers.

\section{Results}

\subsection{Current Use of BCs in Low Resource Settings}

Only half $(4 / 8,50 \%)$ of the interviewees worked at sites currently operating a BC system (Table 1$)$. Sites were donor-supported and not typical of most hospitals in their countries. The remaining stakeholders $(n=4)$ had in-depth knowledge of settings or facilities representative of their region, though their current sites were not actively performing BC. A multitude of challenges were described by all (Table 2) and these challenges were then used to inform the TPP characteristics outlined below. Of the four sites performing BCs, only one was open $24 / 7$, and this was a reference level health facility. 
Three of four sites performed Gram stains on positive BCs. Reliable patient identification was raised as a point of concern in multiple settings as many patients do not know their birthdate, names are often very similar, and many countries do not have national identification numbers or effective hospital patient numbering systems. All four BC sites were collecting blood from patients by syringe and needle following skin decontamination with alcohol and/or iodine. Only $(2 / 4,50 \%)$ had access to "butterfly" needles for difficult and pediatric draws. Their use was impeded by the additional cost. Failure to collect the recommended blood volume was commonplace $(7 / 8,88 \%)$, despite standard guidelines for $\mathrm{BC}$ in adults recommending drawing $10 \mathrm{~mL}$ of blood in two bottles (total $20 \mathrm{~mL}$ ), two to three times [21]. In many settings described in the interviews, this is not common practice and usually only one bottle is collected. In some locations, particularly in Southeast Asia interviewees described a general reluctance to draw large volumes of blood. The information collected in the interviews was used to develop this preliminary TPP (Table 3). Describing the challenges and translating the current shortcomings into technical requirements in the TPP characteristics aims to inform researchers and provide the basis for transformative innovation.

\subsection{Target Product Profile}

\subsubsection{Scope of the test}

Stakeholders emphasized the importance of BCs in providing data for pathogen and AMR surveillance and in improving local empiric treatment guidelines. Based on the stakeholders' input, the target population was defined as: All patients presenting with fever, including neonates and immunocompromised individuals. The acceptable target user was defined as a moderately trained technician, with 3-6 months of training. This was specified because several $(3 / 8,38 \%)$ respondents noted that staff retention was a significant barrier. Stakeholders agreed that BC systems should be available at level 2 facilities. For all but one site (Lao PDR) in which a long-term research project supported BCs, patients were required to pay for BCs. The acceptable per test cost was determined to be $<\$ 10$ USD, with $<\$ 5$ USD desired if BCs are predominantly used to inform patient care.

\subsubsection{Test Performance}

Interviewees agreed that a simplified system should include automated detection of a positive culture and ideally be able to identify pathogens and perform AST. The diagnostic accuracy values were estimated and set to $>95 \%$ sensitivity for detection of positive BC using standard blood culture methodologies, for either a mono-microbial or a poly-microbial infection. The ability to distinguish poly- from mono-microbial infection was considered an optimal requirement. TPP requirements for interfering substances were specifically drafted to address conditions common to LMICs, such as the frequent use of over the counter antibiotics [27] and malaria coinfection.

\subsubsection{Test Procedure}

All interviewees reported a preference for systems that would reduce staff errors and training requirements and increase clinician trust in $\mathrm{BC}$ results. The TPP characteristics were informed by the level of staff training and test complexity typical to level two facilities based on predefined criteria for microscopy centers [19]. Blood sample collection was consistently reported to be a challenge and stakeholders reported inadequate training and complex blood collection procedures resulting in contamination rates as high as $15 \%$ (reported range: $5-10 \%$ ), compared to $3-5 \%$ in the USA or Europe and an international target of 2-3\% [22,32]. To address cases where significant sample transport time or delayed entry into an automated system may occur, incubation of culture bottles at $35^{\circ} \mathrm{C}$ was preferred. All sites reported inadequate or non-existent quality control of $\mathrm{BC}$ bottles or media. For sites that prepared their own media, half reported minimal checks for sterility of the media preparation. In one country, media is purchased by many laboratories from one centralized manufacturer, which does extensive quality control on culture media. 
Table 1. Overview of blood culture (BC) methods in use at interviewed sites or representative countries. Only aerobic cultures were performed across all sites, and bottles were incubated for seven days. Costs at interview sites ranged from a cost of \$5-7 USD per test and up to \$25 USD was reported in one case. All sites currently performing BCs reported that nurses were the primary health providers collecting blood samples, though at some sites physicians ( $2 / 4,50 \%)$ and lab technicians $(1 / 4,25 \%)$ also collecting samples. The expertise of the interviewees from the different countries were infectious disease physicians (Lao PDR, Myanmar, Cambodia), public health/clinical microbiologist (Ethiopia, Botswana).

\begin{tabular}{|c|c|c|c|c|c|c|c|c|}
\hline City, County & Level [22] & $\begin{array}{l}\text { Current } \\
\text { System }\end{array}$ & $\begin{array}{l}\text { Media } \\
\text { Preparation }\end{array}$ & Delayed Entry & QC of Reagents & Reporting Protocol & Identification & AST \\
\hline $\begin{array}{l}\text { Vientiane, Lao } \\
\text { PDR }\end{array}$ & $3-4$ & $\begin{array}{l}\text { Manual, } \\
\text { daily check } \\
\text { for turbidity; } \\
\text { blood }\end{array}$ & Local & $\begin{array}{l}\text { Sample transport from remote locations, } \\
\text { try to receive within } 24 \text { hours of } \\
\text { collection; transport ta RT in a } \\
\text { double-skinned insulated metal box }\end{array}$ & $\begin{array}{l}\text { QC for agar made } \\
\text { in-house }\end{array}$ & $\begin{array}{l}\text { Gram stain, some rapid dx tests } \\
\text { performed and the preliminary result is } \\
\text { communicated verbally to clinicians } \\
\text { ASAP and updated on a daily basis until } \\
\text { there is a written a final report }\end{array}$ & $\mathrm{API}^{\circledR}$ (bioMerieux) & Disk diffusion \\
\hline $\begin{array}{l}\text { Multiple, } \\
\text { Cambodia }\end{array}$ & 3 & $\begin{array}{l}\text { Manual, } \\
\text { daily check } \\
\text { for turbidity }\end{array}$ & Local & Ideally immediate; transport at RT & $\begin{array}{l}\text { Central QC for media } \\
\text { at manufacturer }\end{array}$ & $\begin{array}{l}\text { Lab to call ward to inform doctor of } \\
\text { result }\end{array}$ & Manual biochemical & Disk diffusion \\
\hline $\begin{array}{l}\text { Gondar, } \\
\text { Ethiopia }\end{array}$ & $3-4$ & $\begin{array}{l}\text { Manual, } \\
\text { daily check } \\
\text { for turbidity }\end{array}$ & Local & $\begin{array}{l}\text { Ideally immediate, can be small delays; } \\
\text { transport at RT }\end{array}$ & $\begin{array}{l}\text { QC on media for } \\
\text { sterility }\end{array}$ & $\begin{array}{c}\text { Preliminary reports: growth } \\
\text { (turbidity)-report Gram stain } \\
\text { preliminary report, and finally drug } \\
\text { susceptibility }\end{array}$ & $\begin{array}{l}\text { Gram stain and then } \\
\text { biochemical tests for Gram } \\
\text { negative organism }\end{array}$ & Disk diffusion \\
\hline $\begin{array}{l}\text { Gaborone, } \\
\text { Botswana }\end{array}$ & 4 & $\begin{array}{l}\text { Manual, } \\
\text { daily check } \\
\text { for turbidity }\end{array}$ & Procure & $\begin{array}{l}\text { Ideally immediate, though delays up to } \\
8 \mathrm{~h} \text {; transport at RT }\end{array}$ & QC on media & $\begin{array}{l}\text { Positive results reported in Laboratory } \\
\text { Information Systems for some facilities; } \\
\text { but manual reports are collected by } \\
\text { hospital wards daily }\end{array}$ & Manual biochemical & Disk diffusion \\
\hline $\begin{array}{l}\text { Multiple, } \\
\text { Myanmar }\end{array}$ & $3-4$ & $\begin{array}{l}\text { Majority are } \\
\text { manual }\end{array}$ & Local & $\begin{array}{l}\text { Overnight delays }>12 \mathrm{~h} \text { are common; } \\
\text { transport at RT }\end{array}$ & No & Final report ( $\sim$ days) & $\begin{array}{l}\text { Manual Biochemical (few } \\
\text { level } 4 \text { centers are } \\
\text { introducing Vitek2) }\end{array}$ & $\begin{array}{l}\text { Disk diffusion (automated methods } \\
\text { available for selected patients at very } \\
\text { few Level } 4 \text { centers) }\end{array}$ \\
\hline
\end{tabular}

ASAP: As soon as possible; dx: Diagnosis; QC: Quality control; RT: Room temperature; AST: Antimicrobial susceptibility testing.

Table 2. Summary of challenges for performing BC in low-resource settings, based on responses from interviewed specialists in multiple countries. Responses were subjective assessments by the interviewed and are not necessarily transferrable to all settings in the respective country. The following definitions for three colors were used: Green = no challenge, yellow $=$ some challenges, red $=$ significant challenges, white $=$ unsure/question not answered. The expertise of the interviewees from the different countries were infectious disease physicians (Lao PDR, Myanmar, Cambodia), public health/clinical microbiologist (Ethiopia, Botswana, Guinea) and clinical researcher (DR Congo).

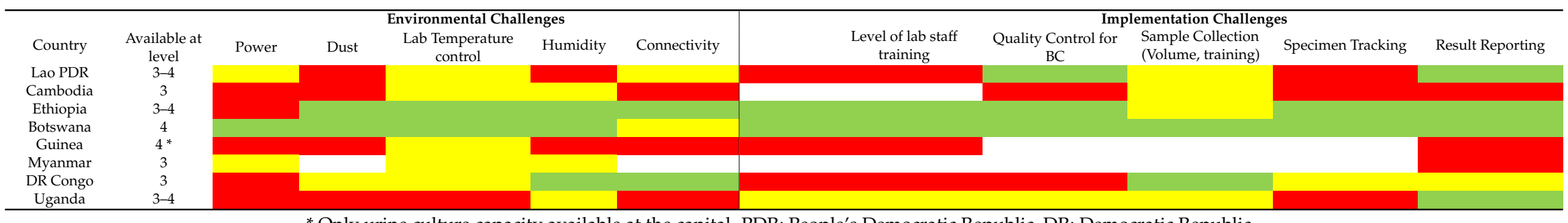

* Only urine culture capacity available at the capital. PDR: People's Democratic Republic, DR: Democratic Republic. 
Table 3. Proposed target product profile for a simplified BC system based on stakeholder input and international guidelines.

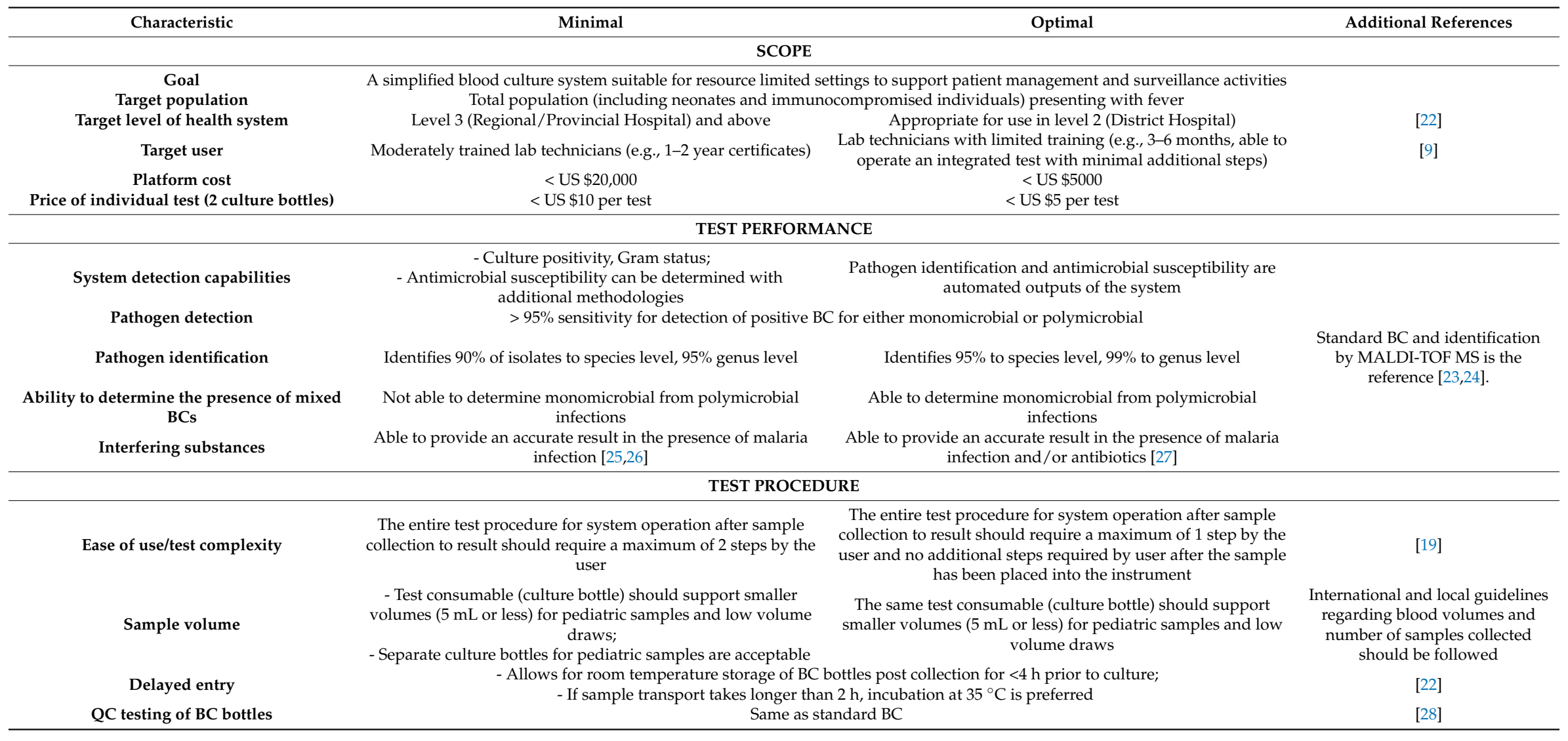


Table 3. Cont.

\begin{tabular}{|c|c|c|c|}
\hline Characteristic & Minimal & Optimal & Additional References \\
\hline \multicolumn{4}{|c|}{ TEST RESULTS } \\
\hline Preliminary result & Test reports positive or negative culture results & $\begin{array}{c}\text { Test reports culture positive and > 95\% Gram status and } \\
\text { morphology information }\end{array}$ & \\
\hline Final result & Provides pathogen identification & $\begin{array}{c}\text { Provides pathogens identification with resistance categories of } \\
\text { interest (MRSA vs. MSSA, ESBL producing Enterobacteriaceae) } \\
\text { and CRE }\end{array}$ & [29] \\
\hline Antimicrobial susceptibility testing & $\begin{array}{l}\text { Antimicrobial susceptibility determination requires separate } \\
\text { methodologies }\end{array}$ & $\begin{array}{l}\text { Antimicrobial susceptibility is included as an automated } \\
\text { output of the test result and therapy recommendations based } \\
\text { on local treatment guidelines }\end{array}$ & \\
\hline Data interpretation and output & $\begin{array}{l}\text { - Alert for preliminary and final report; } \\
\text { - Capable of paper-based and electronic results to not only } \\
\text { laboratory, but physician and ward of patient }\end{array}$ & $\begin{array}{l}\text { Minimal requirements in addition to therapy recommendations } \\
\text { based on local treatment guidelines }\end{array}$ & \\
\hline \multicolumn{4}{|c|}{ CONSUMABLES } \\
\hline Sample collection components & None provided & $\begin{array}{l}\text { All components required for sample collection are included in } \\
\text { the kit }\end{array}$ & \\
\hline BC bottles & $\begin{array}{l}\text { Only compatible with } \mathrm{BC} \text { media bottles from the test } \\
\text { manufacturer }\end{array}$ & $\begin{array}{l}\text { Compatible with local manufacture of } \mathrm{BC} \text { media bottles with a } \\
\text { specified media formulation }\end{array}$ & \\
\hline Sample tracking/Patient identification & Compatible with 2D barcodes and labels & Stakeholder interviews & \\
\hline Storage conditions of BC bottles & $\begin{array}{c}6 \text { months at }+5^{\circ} \mathrm{C} \text { to } 35^{\circ} \mathrm{C}, 70 \% \text { humidity, including transport } \\
\text { stress }\left(48 \text { h at } 50^{\circ} \mathrm{C}\right) \text {; no cold chain required }\end{array}$ & $\begin{array}{l}12 \text { months at }+5^{\circ} \mathrm{C} \text { to }+40^{\circ} \mathrm{C} \text { at } 90 \% \text { humidity \& transport } \\
\text { stress }\left(72 \mathrm{~h} \text { at } 50{ }^{\circ} \mathrm{C}\right) \text {; no cold chain required }\end{array}$ & $\begin{array}{c}\text { High environmental } \\
\text { temperatures and high humidity } \\
\text { is often a problem in many } \\
\text { countries. High environmental } \\
\text { temperatures and high humidity } \\
\text { is often a problem in many } \\
\text { countries [30]. }\end{array}$ \\
\hline Shipping conditions of consumables \& kit & $\begin{array}{l}\text { No cold chain required; tolerance of transport stress for a } \\
\text { minimum of } 48 \text { h at } 5^{\circ} \mathrm{C} \text { to }+40^{\circ} \mathrm{C}\end{array}$ & $\begin{array}{l}\text { No cold chain required; tolerance of transport stress for a } \\
\text { minimum of } 72 \mathrm{~h} \text { at } 5{ }^{\circ} \mathrm{C} \text { to }+40^{\circ} \mathrm{C}\end{array}$ & $\begin{array}{l}\text { Refrigerated transport is costly } \\
\text { and often cannot be guaranteed } \\
\text { during the entire transportation } \\
\text { process. Frequent delays in } \\
\text { transport are commonplace [30]. }\end{array}$ \\
\hline Waste disposal & \multicolumn{2}{|c|}{$\begin{array}{l}\text { Consumables should be able to be disposed of as biohazardous waste as specified by WHO guidelines according to the safe } \\
\text { management of waste from health-care activities or per country regulations }\end{array}$} & {$[31]$} \\
\hline
\end{tabular}


Table 3. Cont

\begin{tabular}{|c|c|c|c|}
\hline Characteristic & Minimal & Optimal & Additional References \\
\hline \multicolumn{4}{|c|}{ OPERATIONAL CHARACTERISTICS } \\
\hline Biosafety & $\begin{array}{l}\text { Same as standard BC in a closed system; } \\
\text { Biosafety alert is provided when a pathogen identified is on a } \\
\text { predefined biosafety list }\end{array}$ & $\begin{array}{c}\text { - No need for a biosafety cabinet; basic safety procedures need } \\
\text { to be followed (standard PPE); } \\
\text { - Alarms present for organisms that pose a biosafety risk for } \\
\text { laboratory acquired infections }\end{array}$ & \\
\hline Operating conditions & $\begin{array}{l}\text { - Between }+10^{\circ} \mathrm{C} \text { to }+35^{\circ} \mathrm{C} \text { at } 70 \% \text { humidity and at a max } \\
\text { altitude of } 2000 \text { meters above mean sea level; } \\
\text { - Ability to function in a high dust environment, with manual } \\
\text { cleaning via standard lab consumable clean wipes or cleaning } \\
\text { tool provided with the instrument }\end{array}$ & $\begin{array}{c}\text { - Between }+5^{\circ} \mathrm{C} \text { to }+40^{\circ} \mathrm{C} \text { at } 90 \% \text { humidity and at a max } \\
\text { altitude of } 3000 \text { meters above mean sea level; } \\
\text { - Ability to function in a high dust environment with minimal } \\
\text { manual cleaning required by user }\end{array}$ & $\begin{array}{l}\text { High environmental } \\
\text { temperatures and high humidity } \\
\text { and dust are often an issue in } \\
\text { LMICs. High environmental } \\
\text { temperatures and high humidity } \\
\text { and dust are often an issue in } \\
\text { LMICs. }\end{array}$ \\
\hline
\end{tabular}

protective equipment. 


\subsubsection{Test Results}

To inform the TPP characteristics related to test results, we discussed how BC results were reported in each facility (Table 1). Results were not available in a timely fashion because the laboratory did not often communicate preliminary results at six of eight sites (75\%). As a minimum requirement, reporting of preliminary results of a positive BC, ideally with Gram stain information, is required to inform clinical decisions as quickly as possible. For the minimal requirements, results from antimicrobial susceptibility testing by a separate method were acceptable. However, interviewees unanimously expressed an interest in automated AST information from an integrated simplified BC system, which was included as the desired characteristic. The addition of therapy recommendations based on local treatment guidelines to accompany $\mathrm{BC}$ test results was mentioned as a useful addition to facilitate treatment guidance for clinicians by $3 / 8(38 \%)$ interviewees and was included as an optimal requirement for data interpretation and output.

\subsubsection{Consumables and Operational Characteristics}

The optimal requirement calls for inclusion of sample collection supplies with the BC bottle test kit to address this limitation. Media formulations can have significant impact on a technology's detection method, hence, the minimal requirement was restricted to compatibility of a designated manufacturer's BC bottle and the optimal case would allow for locally produced media formulations. Several sites expressed an interest in biosafety alerts for hazardous agents including Burkholderia pseudomallei, Brucella spp., and Bacillus anthracis.

\subsubsection{Cultural Considerations Beyond the TPP}

A recurring theme brought up by the specialists was that technology solutions alone will not address all the challenges currently impeding the use of BCs in resource-limited settings. Even if a timely result was provided to clinicians, stakeholders reported that a lack of trust in results often leads clinicians to ignore laboratory results in their decision-making. Stakeholders suggested that clinicians need education on the use of empiric therapy guidelines and BCs, since limited availability of quality BC facilities can result in a lack of knowledge and training. There is a need to educate clinicians to drive demand for $\mathrm{BC}$ from the clinician, not from the laboratory, and regularly enhanced laboratory-ward/outpatient clinical liaison. Further, supply chain issues, stock-outs, and bureaucratic challenges are barriers for diagnostic and therapeutic availability. Based on the small sample number, it appeared that supply chain issues were more prevalent in Asia.

\section{Discussion}

Faster and more accurate diagnosis of bloodstream infections in low-resource areas is critical for effective patient management, surveillance of AMR, and development of local empiric therapy guidelines. For example, based on the interview feedback Guinea, a county of 12.4 million inhabitants, does not have a microbiology facility capable of performing pathogen ID and AST, even at the highest level of the health system. This results in a lack of data to inform treatment and public health interventions [11]. In parallel to the work reported here, the BACTI-LRS consortium also highlighted this need in a similar initiative, which explored requirements to implement bacteriology in resource-limited setting LMICs [8].

The aim of the current report was to identify the challenges and gaps to performing BCs and suggest how new innovations could address them in the form of a simplified BC system. Although this is one solution to the problem, the general lack of laboratory capacity, supply chain constrains, and human and infrastructure hurdles remain, and need to be addressed in parallel. Albeit anecdotal, interviewees hinted at overall improved supply chains following the U.S. President's Emergency Plan for AIDS Relief (PEPFAR) initiative that also resulted in better microbiology supply access. This is encouraging and demonstrates that barriers can be overcome if global health players unite around 
the same goals. In addition to the technical and capacity challenges reported by the interviewees, our findings highlight the cultural issues and the need for continued education around the use, utility and safety of BCs.

Although this report adds new knowledge on the technical needs, the work also has limitations that might have introduced bias and might justify additional work and consensus building if this work results in significant interest by product development partners. In brief, our interviews included only a small number of stakeholders representing two continents who might have given a narrow view of the situation. Further, the interview team assumed that current systems are suboptimal, potentially further introducing bias. Although this is possible, recent publications have identified the lack of quality data on AMR and large international initiatives (e.g., Fleming Fund, UK) are underway to bridge the challenges reported here $[8,10,11,33,34]$. This suggests that problems highlighted in our small sample set are to a large degree transferable beyond the 'interviewees' countries and setting. In addition, the TPP might have been influenced by preconceived notions of what a simplified BC tool should look like. However, given the separation of minimum and optimal criteria, as well as an extensive list of 33 characteristics, it is believed that the TPP will be widely applicable and lessons learned here can be applied to BC systems.

The vision for the TPP is to simplify work for the laboratory needs, while not necessarily being simple for the innovator. In general, despite the daunting list of requirements, it should be noted that a system that meets a subset of the characteristics and is designed with the procurement and capacity challenges of resource-limited settings in mind would be a substantial improvement on current BC systems.

In conclusion, a simplified BC system would enable expanded use of BCs in low-resource areas. $\mathrm{BC}$ is an essential tool to inform treatment and management of bloodstream infection and the interviews with different stakeholders highlighted the continued need for phenotypic detection tools beyond diagnostic tools that can only identify selected pathogens and resistance markers. Tools like these provide crucial surveillance information that is currently largely unavailable in LIMCs [11]. To ensure that all these tools are available, a joint effort from academia and industry, as well as global health organizations, is needed to seed the pipeline of innovations and ensure that infrastructures at all levels of the health care system are in place to accept improved BC technology. In an ideal scenario, these improved capacities extend beyond the reference level and cover all levels of the health system to ensure all severely sick patients in need of appropriate treatment at hospitals can receive a diagnostic test that will inform the choice of antibiotics for improved outcomes, as well as fostering antibiotic stewardship and AMR surveillance.

Supplementary Materials: The following are available online at http:/ /www.mdpi.com/2075-4418/9/1/10/s1.

Author Contributions: S.D. conceived the study idea. J.O. and P.J.D. data collection and target product profile (TPP) development. P.N.N., D.A.B.D., B.T., E.J.B., D.F., C.F., Y.C.M., M.M., E.A.A., and C.I. provided information and supported the TPP development as specialists. J.O., P.J.D., S.D., and C.I. data interpretation. J.O. and P.J.D. prepared the first draft of the manuscript and all authors reviewed and contributed to the final version.

Acknowledgments: We would like to thank the UK Aid from the British people for supporting this work. D.A.B.D. and P.N.N. are supported by Wellcome. Further we would like to thank Ray Martino from Specific Technologies for the fruitful discussions throughout this project.

Conflicts of Interest: The authors declare no conflict of interest, although FIND was at the time working with commercial partners on the improvement of a diagnostic tool in this space.

\section{References}

1. WHA. Improving the Prevention, Diagnosis and Clinical Management of Sepsis. Available online: http:/ / apps.who.int/gb/ebwha/pdf_files/WHA70/A70_R7-en.pdf (accessed on 28 December 2018).

2. Penno, E.C.; Baird, S.J.; Crump, J.A. Cost-Effectiveness of Surveillance for Bloodstream Infections for Sepsis Management in Low-Resource Settings. Am. J. Trop. Med. Hyg. 2015, 93, 850-860. [CrossRef] [PubMed] 
3. Liu, L.; Johnson, H.L.; Cousens, S.; Perin, J.; Scott, S.; Lawn, J.E.; Rudan, I.; Campbell, H.; Cibulskis, R.; Li, M.; et al. Global, regional, and national causes of child mortality: an updated systematic analysis for 2010 with time trends since 2000. Lancet 2012, 379, 2151-2161. [CrossRef]

4. Cohen, J.; Vincent, J.L.; Adhikari, N.K.; Machado, F.R.; Angus, D.C.; Calandra, T.; Jaton, K.; Giulieri, S.; Delaloye, J.; Opal, S.; et al. Sepsis: a roadmap for future research. Lancet. Infect. Dis. 2015, 15, 581-614. [CrossRef]

5. Dunne, M.; Burnham, C.-A.D. The Dark Art of Blood Cultures; American Society for Microbiology: Washington, DC, USA, 2017. [CrossRef]

6. Wilson, M.L.; Weinstein, M.P.; Reller, L.B. Chapter 3: Laboratory Detection of Bacteremia and Fungemia. In Manual of Clinical Microbiology, 11th ed.; American Society for Microbiology: Washington, DC, USA, 2015. [CrossRef]

7. Loonen, A.J.; Wolffs, P.F.; Bruggeman, C.A.; van den Brule, A.J. Developments for improved diagnosis of bacterial bloodstream infections. Eur. J. Clin. Microbiol. Infect. Dis. 2014, 33, 1687-1702. [CrossRef] [PubMed]

8. Ombelet, S.; Ronat, J.-B.; Walsh, T.; Yansouni, C.P.; Cox, J.; Vlieghe, E.; Martiny, D.; Semret, M.; Vandenberg, O.; Jacobs, J.; et al. Clinical bacteriology in low-resource settings: today's solutions. The Lancet Infectious Diseases 2018, 18, e248-e258. [CrossRef]

9. Petti, C.A.; Polage, C.R.; Quinn, T.C.; Ronald, A.R.; Sande, M.A. Laboratory medicine in Africa: a barrier to effective health care. Clin. Infect. Dis. 2006, 42, 377-382. [CrossRef] [PubMed]

10. Schroeder, L.F.; Amukele, T. Medical laboratories in sub-Saharan Africa that meet international quality standards. Am. J. Clin. Pathol. 2014, 141, 791-795. [CrossRef] [PubMed]

11. Tadesse, B.T.; Ashley, E.A.; Ongarello, S.; Havumaki, J.; Wijegoonewardena, M.; Gonzalez, I.J.; Dittrich, S. Antimicrobial resistance in Africa: a systematic review. BMC Infect. Dis. 2017, 17, 616. [CrossRef] [PubMed]

12. Teerawattanasook, N.; Tauran, P.M.; Teparrukkul, P.; Wuthiekanun, V.; Dance, D.A.B.; Arif, M.; Limmathurotsakul, D. Capacity and Utilization of Blood Culture in Two Referral Hospitals in Indonesia and Thailand. Am. J. Trop. Med. Hyg. 2017, 97, 1257-1261. [CrossRef]

13. Guarner, J.; Amukele, T.; Mehari, M.; Gemechu, T.; Woldeamanuel, Y.; Winkler, A.M.; Asrat, D.; Wilson, M.L.; del Rio, C. Building capacity in laboratory medicine in Africa by increasing physician involvement: A laboratory medicine course for clinicians. Am. J. Clin. Pathol. 2015, 143, 405-411. [CrossRef]

14. LSTM. An Analysis of Approaches to Laboratory Capacity Strengthening for Drug Resistant Infections in Low and Middle Income Countries. Available online: https: / www.lstmed.ac.uk/sites/default/files / centre/Lab\%20capacity\%20strengthening\%20-\%20summary\%20-\%20public\%5B1\%5D.pdf (accessed on 8 January 2019).

15. CDC. Global Health Security Agenda: GHSA National Laboratory System Action Package (GHSA Action Package Detect-1). Available online: https:/ /www.cdc.gov/globalhealth/security/actionpackages/ national_laboratory.htm (accessed on 10 January 2019).

16. Seale, A.C.; Hutchison, C.; Fernandes, S.; Stoesser, N.; Kelly, H.; Lowe, B.; Turner, P.; Hanson, K.; Chandler, C.I.R.; Goodman, C.; et al. Supporting surveillance capacity for antimicrobial resistance: Laboratory capacity strengthening for drug resistant infections in low and middle income countries. Wellcome Open Res. 2017, 2, 91. [CrossRef] [PubMed]

17. WHO. High-Priority Target Product Profiles for New Tuberculosis Diagnostics: Report of a Consensus Meeting. Available online: http:/ /www.who.int/tb/publications/tpp_report/en/ (accessed on 29 February 2016).

18. Dittrich, S.; Tadesse, B.T.; Moussy, F.; Chua, A.; Zorzet, A.; Tangden, T.; Dolinger, D.L.; Page, A.L.; Crump, J.A.; D'Acremont, V.; et al. Target Product Profile for a Diagnostic Assay to Differentiate between Bacterial and Non-Bacterial Infections and Reduce Antimicrobial Overuse in Resource-Limited Settings: An Expert Consensus. PLoS ONE 2016, 11, e0161721. [CrossRef] [PubMed]

19. Denkinger, C.M.; Dolinger, D.; Schito, M.; Wells, W.; Cobelens, F.; Pai, M.; Zignol, M.; Cirillo, D.M.; Alland, D.; Casenghi, M.; et al. Target product profile of a molecular drug-susceptibility test for use in microscopy centers. J. Infect. Dis. 2015, 211, S39-S49. [CrossRef] [PubMed]

20. WHO. Consultation on Technical and Operational Recommendations for Clinical Laboratory Testing Harmonization and Standardization. Available online: https:/ /www.who.int/healthsystems/round9_9.pdf (accessed on 8 January 2019).

21. CLSI. Principles and Procedures for Blood Cultures; Approved Guidlines. In CLSI document M47-A; Clinical and Laboratory Standards Institute: Wayne, PA, USA, 2007; Volume 27. 
22. Ghani, A.C.; Burgess, D.H.; Reynolds, A.; Rousseau, C. Expanding the role of diagnostic and prognostic tools for infectious diseases in resource-poor settings. Nature 2015, 528, S50-S52. [CrossRef] [PubMed]

23. Lagace-Wiens, P.R.; Adam, H.J.; Karlowsky, J.A.; Nichol, K.A.; Pang, P.F.; Guenther, J.; Webb, A.A.; Miller, C.; Alfa, M.J. Identification of blood culture isolates directly from positive blood cultures by use of matrix-assisted laser desorption ionization-time of flight mass spectrometry and a commercial extraction system: Analysis of performance, cost, and turnaround time. J. Clin. Microbiol. 2012, 50, 3324-3328. [CrossRef]

24. Faron, M.L.; Buchan, B.W.; Ledeboer, N.A. Matrix-Assisted Laser Desorption Ionization-Time of Flight Mass Spectrometry for Use with Positive Blood Cultures: Methodology, Performance, and Optimization. J. Clin. Microbiol. 2017, 55, 3328-3338. [CrossRef] [PubMed]

25. Aesif, S.W.; Swierzbinski, M.J.; Keiser, J.F. Positive Blood Culture Results After Plasmodium falciparum Diagnosis. Lab. Med. 2014, 45, e89-e91. [CrossRef]

26. de Vries, J.J.; van Assen, S.; Mulder, A.B.; Kampinga, G.A. Positive blood culture with Plasmodium falciparum: case report. Am. J. Trop. Med. Hyg. 2007, 76, 1098-1099. [CrossRef] [PubMed]

27. Khennavong, M.; Davone, V.; Vongsouvath, M.; Phetsouvanh, R.; Silisouk, J.; Rattana, O.; Mayxay, M.; Castonguay-Vanier, J.; Moore, C.E.; Strobel, M.; et al. Urine antibiotic activity in patients presenting to hospitals in Laos: implications for worsening antibiotic resistance. Am. J. Trop. Med. Hyg. 2011, 85, $295-302$. [CrossRef]

28. CLSI. Quality Control for Commercially Prepared Microbiological Culture Media; Approved Standard-3rd Edition. In CLSI document M22-A3; Clinical Laboratory Standards Institute: Wayne, PA, USA, 2004.

29. WHO. Global Priority List of Antibiotic-Resistant Bacteria to Guide Research, Discovery, and Development of New Antibiotics. Available online: https://www.who.int/medicines/publications/global-priority-listantibiotic-resistant-bacteria/en/ (accessed on 8 January 2019).

30. FIND. High-priority Target Product Profile for Hepatitis C Diagnosis in Decentralized Settings: Report of a Consensus Meeting. Available online: https://www.finddx.org/wp-content/uploads/2016/01/HCV-TPPReport_17July2015_final.pdf (accessed on 8 January 2019).

31. WHO. Safe Management of Wastes from Health-care Activities. Available online: https://www.who.int/ water_sanitation_health/publications/wastemanag/en/ (accessed on 8 January 2019).

32. Bentley, J.; Thakore, S.; Muir, L.; Baird, A.; Lee, J. A change of culture: reducing blood culture contamination rates in an Emergency Department. BMJ Qual. Improv. Rep. 2016, 5. [CrossRef]

33. Barbe, B.; Yansouni, C.P.; Affolabi, D.; Jacobs, J. Implementation of quality management for clinical bacteriology in low-resource settings. Clin. Microbiol. Infect. 2017, 23, 426-433. [CrossRef] [PubMed]

34. WHO. Global Antimicrobial Resistance Surveillance System (GLASS). Available online: https:/ /www.who. int/glass/en (accessed on 8 January 2019). 